\title{
PRÁTICAS INTERDISCIPLINARES DE EDUCAÇÃO EM SAÚDE E MEIO AMBIENTE NA EDUCAÇÃO DE JOVENS E ADULTOS: PERCEPÇÃO DOS ALUNOS
}

\author{
PRÁCTICAS INTERDISCIPLINARES DE EDUCACIÓN EN SALUD Y MEDIO \\ AMBIENTE EN LA EDUCACIÓN DE JÓVENES Y ADULTOS: PERCEPCIÓN DE LOS \\ ALUMNOS
}
HEALTH AND ENVIRONMENT INTERDISCIPLINARY EDUCATION PRACTICES IN THE YOUTH AND ADULT EDUCATION: STUDENTS PERCEPTION

\author{
Elisa Angélica Alves GUEDES ${ }^{1}$ \\ Marianne Louise Marinho MENDES ${ }^{2}$ \\ Cristhiane Maria Bazílio de Omena MESSIAS ${ }^{3}$
}

RESUMO: O estudo busca apresentar a percepção de alunos da modalidade de ensino Educação de Jovens e Adultos mediante práticas interdisciplinares de educação em saúde e meio ambiente. Trata-se de um estudo de abordagem qualitativa e inspiração etnográfica. Foram realizadas práticas interdisciplinares e entrevistas com os alunos. A aprendizagem acerca dos temas propostos, mediante a prática interdisciplinar, contribuiu para a aquisição de conhecimentos, visto que tal prática contempla também seus conhecimentos prévios. Considera-se que a interdisciplinaridade, em conjunto com as temáticas propostas, foi percebida como uma metodologia inovadora que possibilita um olhar crítico acerca de mudanças na postura do aluno em relação à saúde e o meio ambiente.

PALAVRAS-CHAVE: Práticas interdisciplinares. Educação em saúde. Educação em meio ambiente. Educação de Jovens e Adultos.

RESUMEN: El estudio plantea presentar la percepción de los alumnos de la modalidad de la enseñanza Educación de Jóvenes y Adultos mediante prácticas interdisciplinares de educación en salud y medioambiente. Se trata de un estudio de enfoque cualitativo e inspiración etnográfica. Se realizaron prácticas interdisciplinares y entrevistas con los alumnos. El aprendizaje acerca de los temas propuestos, mediante la práctica interdisciplinaria, ha contribuido a la adquisición de conocimientos, ya que tal práctica contempla también sus conocimientos previos. Se discurre que la interdisciplinariedad, en conjunto con las temáticas propuestas, fue percibida como una metodología innovadora que posibilita una mirada crítica acerca de cambios en la postura del alumno en relación a la salud y el medioambiente.

${ }^{1}$ Universidade de Pernambuco - (UPE), Petrolina - PE - Brasil. Mestre em Educação Profissional pelo Programa de Pós-Graduação em Formação de Professores e Práticas Interdisciplinares (PPGFPPI). ORCID: <http://orcid.org/0000-0001-7106-6347>. E-mail: elisa.guedes80@hotmail.com.

${ }^{2}$ Universidade de Pernambuco - (UPE), Petrolina - PE - Brasil. Professora Adjunta do curso de Nutrição e do Programa de Pós-Graduação em Formação de Professores e Práticas Interdisciplinares - PPGFPPI. ORCID: <http://orcid.org/0000-0003-1560-765X>. E-mail: marianne.marinho@upe.br

${ }^{3}$ Universidade de Pernambuco - (UPE), Petrolina - PE - Brasil. Professora Adjunta do curso de Nutrição e do Programa de Pós-Graduação em Formação de Professores e Práticas Interdisciplinares - PPGFPPI. ORCID: <http://orcid.org/0000-0002-1991-0376>.E-mail: cristhiane.omena@upe.br

RIAEE - Revista Ibero-Americana de Estudos em Educação, Araraquara, v. 14, n. 3, p. 1030-1048, jul./set., 2019. e-ISSN: 1982-5587. 
PALABRAS CLAVE: Prácticas interdisciplinares. Educación en salud. Educación en el medioambiente. Educación de Jóvenes y Adultos.

ABSTRACT: The study aims to present students' perception of the modality of Youth and Adults Education through interdisciplinary practices of education in health and environment. This is a study of qualitative approach and ethnographic inspiration. Interdisciplinary practices and interviews with students were carried out. The learning about the proposed subjects, through interdisciplinary practice, contributed to the acquisition of knowledge, as this practice also contemplates their previous knowledge. Interdisciplinarity considered, together with the proposed themes, was perceived as an innovative methodology that allows a critical look at changes in the student's posture regarding health and the environment.

KEYWORDS: Interdisciplinary practices. Health education. Environmental education. Youth and Adult Education.

\section{Introdução}

A Educação de Jovens e Adultos (EJA), na perspectiva da educação ao longo da vida, requer uma abordagem curricular próxima e adequada às demandas da realidade que envolvem os educandos no processo de construção de conhecimentos, a partir do acúmulo de saberes e experiências que os alunos já trazem consigo como síntese da sua própria vida (ARROYO, 2006).

Trata-se de uma modalidade de educação que está fundamentada a partir da Lei de Diretrizes e Bases da Educação Nacional (LDBEN), Lei n 9394/96, sendo destinada aos alunos jovens e adultos que não tiveram acesso ou continuidade de estudos no Ensino Fundamental e Médio na idade apropriada (BRASIL, 1996).

Nesse ínterim, alunos que se enquadram nessa modalidade de ensino necessitam de uma pedagogia sustentada nas relações, nas interações e nas práticas educativas que agucem seus interesses pelo novo conhecimento a ser construído. Para tanto, um dos métodos que abarcam tal metodologia consiste no diálogo entre as diferentes áreas de ensino, superando a ideia de transmissão de conteúdos e caminhando para uma abordagem interdisciplinar para que as temáticas trabalhadas, bem como a metodologia trabalhada nos conteúdos, possam ser eficazes (SÃO PAULO, 2015).

A interdisciplinaridade consiste em um método de ensino que tem sido discutida em vários campos da educação e é compreendida na literatura como importante intervenção educativa e passível de questionarmos acerca da prática educativa. Entretanto, inserir a prática interdisciplinar no ato de ensinar é considerado um dos desafios para a educação, visto que esta 
tem por objetivo aguçar cada vez mais o prazer pelo novo conhecimento a ser adquirido (FAZENDA, 2014).

Para Freire (2011), a interdisciplinaridade contempla um processo metodológico de construção do conhecimento pelo sujeito com base em sua relação com o contexto em que ele convive, com sua realidade e a cultura que o cerca. $\mathrm{O}$ mesmo autor ainda considera que, quando se trata do ato de educar jovens e adultos, devem ser consideradas características e conhecimentos próprios desses sujeitos, uma vez que estes já passaram, e ainda passam, pelo processo contínuo de conhecimentos que devem ser considerados no momento da aprendizagem. Ainda com relação à interdisciplinaridade, Thiesen (2008) afirma que essa prática envolve a caracterização de dois movimentos dialéticos: a problematização da situação, pela qual se desvela a realidade, e a sistematização dos conhecimentos de forma integrada.

A literatura ressalta também que a perspectiva interdisciplinar visa à recuperação da unidade humana através da passagem de uma subjetividade para uma intersubjetividade do sujeito e, assim sendo, recupera a formação do homem em sua totalidade, cabendo à escola o papel de formação do homem inserido em sua realidade e como agente das mudanças do mundo. Portanto, mais do que identificar um conceito para interdisciplinaridade, o que os autores buscam é encontrar seu sentido epistemológico, seu papel e suas implicações sobre o processo do conhecer (FAZENDA, 1994).

Considerando, de acordo com a literatura, que a prática interdisciplinar contempla a escola como o locus para a realização de tal prática, sugere-se que as temáticas a serem trabalhadas sejam as que possibilitem o trabalho do conteúdo didático de forma integrada entre professores de outras disciplinas ou de que o professor de uma mesma disciplina trabalhe temáticas diversificadas. As temáticas também podem ser definidas partindo dos temas transversais descritos nos Parâmetros Curriculares Nacionais da educação básica (PCN's), a saber: ética, pluralidade cultural, orientação sexual, meio ambiente, saúde e temas locais que contemplem o interesse específico de uma determinada realidade a serem definidos no âmbito do estado, da cidade ou mesmo da escola (BRASIL, 1997).

Aplicando a prática interdisciplinar para a modalidade de ensino na Educação de Jovens e Adultos (EJA), Carbonell (2012) também reafirma que o aluno jovem e/ou adulto é um sujeito que traz consigo experiências de vida relevantes a serem consideradas como porta de acesso para o conhecimento escolar. $\mathrm{O}$ afunilamento entre seus conhecimentos prévios e escolares proporcionará uma relação de troca entre os saberes do educando e de seu educador. Portanto, é necessário que o professor esteja atento a como o aluno interage com os diferentes conhecimentos adquiridos em relação com o seu próprio olhar sobre o mundo (MERLEAU- 
PONTY, 1999). Percebe-se, à luz dos autores supracitados, que a prática interdisciplinar vai além da flexibilidade entre as disciplinas escolares, pois contempla, além da aquisição do conhecimento científico, um olhar do sujeito sobre o lugar que ocupa no mundo.

Essa investigação é considerada relevante uma vez que visa a contribuir nas discussões acadêmicas sobre a percepção dos alunos da EJA referente ao método de ensino interdisciplinar. Diante dessa perspectiva, o presente estudo tem por objetivo apresentar a percepção de alunos da modalidade de ensino Educação de Jovens e Adultos (EJA) mediante práticas interdisciplinares de educação em saúde e meio ambiente.

\section{Metodologia}

A coleta dos dados foi realizada com a colaboração de 15 alunos matriculados no $2^{\circ}$ módulo da modalidade EJA de ensino da Escola Estadual Eduardo Coelho, localizada no município de Petrolina-PE durante os meses de fevereiro e julho do ano de 2016. São resultados do projeto de pesquisa intitulado "Práticas Interdisciplinares de Educação em Saúde e Meio Ambiente na Instrução de Jovens e Adultos de uma Instituição de Ensino Público no Município de Petrolina-PE".

Trata-se de um estudo de abordagem qualitativa e de inspiração etnográfica, possuindo como característica própria a visão dos sujeitos pesquisados sobre suas experiências acerca da temática discutida (GIL, 2007). Concernente à pesquisa etnográfica, trata-se de uma pesquisa que fornece os meios para sondar, questionar, descrever e compreender as práticas culturais fundamentadas na intersubjetividade dos que aprendem e dos que facilitam a aprendizagem, no seio de uma instituição específica, no caso, a escola (FINO, 2011). Após a coleta dos dados, os mesmos foram analisados a partir da Análise de Conteúdo, sendo necessário que o pesquisador estivesse atento a três etapas imprescindíveis, as quais são: pré-análise, exploração do material e tratamento e interpretação dos dados coletados (BARDIN, 2009).

A etapa da pré-análise refere-se ao primeiro contato que o pesquisador tem com o contexto da pesquisa. A segunda etapa, exploração de material, é um momento que exige dedicação do pesquisador, por ser a etapa na qual é realizada a organização das unidades de significados e a construção das categorias de análise. A terceira etapa aborda a interpretação dos dados obtidos no campo de pesquisa. Para Bardin (2009), esse momento exige cuidadosa atenção por parte do pesquisador, uma vez que os dados encontrados in locus devem ser tratados de modo significativo, levando em consideração o que foi observado e realizado no campo de 
pesquisa. Desse modo, o investigador poderá, em seguida, realizar a interpretação dos dados coletados.

Foi dado início às atividades práticas interdisciplinares mediante as disciplinas biologia e língua portuguesa, utilizando-se como instrumentos a discussão de textos, oficinas práticas e dinâmica seguidas de discussão em sala sempre ao final de cada atividade, visando a socialização dos conteúdos apresentados. Foram realizados 6 encontros com as seguintes temáticas:

$1^{\text {a) }}$ Alimentação Saudável para Todos: Siga os 10 Passos;

$2^{\text {a }) ~ S a u ́ d e ~ d o ~ T r a b a l h a d o r ; ~}$

$3^{\text {a }) ~ C o r d e l: ~ o ~ D e s a b a f o ~ d o ~ R i o ~ S a ̃ o ~ F r a n c i s c o ; ~}$

4ª Vamos Evitar o Desperdício de Água;

$5^{\text {a) }}$ Preservação do Meio Ambiente;

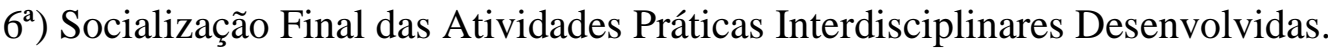

No sexto encontro, foi realizada a socialização de todas as atividades desenvolvidas em sala. As temáticas específicas das práticas interdisciplinares aplicadas foram acordadas entre a demanda dos alunos e o planejamento de aula das professoras e registradas no Diário de Bordo para constante consulta.

Após a realização das atividades interdisciplinares, foram realizadas as entrevistas com as seguintes perguntas norteadoras: 1) Em algum outro momento do curso, algum professor, ou professores, já havia(m) trabalhado com o método interdisciplinar? 2) Para você, houve um melhor desempenho do seu aprendizado com a forma como os conteúdos foram trabalhados? 3) O que você achou de trabalhar as disciplinas de Português e Biologia em um mesmo momento? 4) Os temas trabalhados de educação em saúde e meio ambiente irão contribuir como aprendizagem para sua vida? Nesse item 4, para as respostas afirmativas, foi perguntado sobre quais foram as contribuições.

A aplicação das entrevistas foi realizada na biblioteca da escola, visto tratar-se de um espaço disponibilizado pela própria escola e que os alunos frequentam todos os dias. As entrevistas foram gravadas em aparelho de áudio, modelo smartphone, com duração de aproximadamente 20 minutos. Por fim, todas as entrevistas foram transcritas, reproduzidas da forma mais fiel possível a fala do participante da pesquisa e discutidas com a literatura. Por questões éticas, foram adotados símbolos numéricos para a identificação dos participantes nas respectivas falas dos mesmos.

Para os critérios de inclusão, os sujeitos deveriam estar matriculados na turma do $2^{\circ}$ módulo do ensino EJA na instituição de ensino pesquisada. Seguindo as recomendações do 
Conselho Nacional de Saúde na Resolução 196/96 do Ministério da Saúde, antes da realização da Entrevista Aberta, cada participante foi convidado a assinar o Termo de Consentimento Livre e Esclarecido - TCLE. Apenas os alunos que não participavam efetivamente das aulas, e consequentemente não assinaram o TCLE, foram considerados casos de exclusão da pesquisa devido a não efetividade nas aulas e a não assinatura do termo. $O$ estudo também foi devidamente aprovado pelo Comitê de Ética em Pesquisa ${ }^{4}$.

\section{Resultados e discussão}

\section{$1^{a}$ Atividade Prática Interdisciplinar: Alimentação Saudável para Todos - Siga os 10}

\section{Passos:}

A atividade foi realizada na aula de Língua Portuguesa e abrangeu a apresentação e discussão de uma publicação do Ministério da Saúde (BRASIL, 2013), referente a orientações nutricionais acerca dos nossos hábitos alimentares para pessoas adultas, detalhando em forma de 10 passos como ter uma alimentação saudável, além de incentivar a prática regular de atividade física.

Na semana seguinte, na aula de Biologia, foi aberto espaço para a oficina em que os alunos confeccionaram, em grupo ou individualmente, cartazes com a temática apresentada, ficando a critério de cada equipe, ou aluno, estabelecer os pontos mais relevantes na mudança de seus hábitos alimentares do dia a dia. No mesmo momento, a professora da disciplina, apesar de lecionar a disciplina Biologia, auxiliou os alunos apresentando-lhes a forma correta de escrita de algumas palavras conforme a gramática normativa atual.

\section{$2^{a}$ Atividade prática interdisciplinar: Saúde do Trabalhador:}

Atividade prática desenvolvida na aula de Biologia e de Língua Portuguesa em forma de oficina, sendo discutidos pontos referentes à importância do uso do Equipamento de Proteção Individual (EPI), com base no livro "Ciência, Transformação e Cotidiano: Educação de Jovens e Adultos" (SICRIVANO et al., 2013; p. 286-289), literatura utilizada nas aulas de ciências exatas e da natureza com os alunos da turma locus da pesquisa.

Na aula de Língua Portuguesa e, com base no conteúdo do livro, foram abordados os cuidados que os trabalhadores devem ter com sua saúde e a importância do uso do EPI de acordo com cada função. Foi realizada a leitura oral dos parágrafos do texto e pontuados aspectos da

${ }^{4}$ Comitê de Ética em Pesquisa da instituição proponente Fundação Universidade de Pernambuco (CEP/UPE) sob registro no CAAE de número 49341115.7.0000.5207. 
gramática normativa concernentes à pontuação e à escrita das palavras. Na aula de Biologia, foram distribuídas aos alunos imagens com os perfis de vários personagens fictícios que ocupam diversos tipos de funções em empresas, sendo solicitado aos alunos que eles adequassem as figuras apresentadas aos empregos indicados pelos personagens. Após a atividade, foi aberto espaço para discussão para que eles abordassem o que compreenderam do texto e relacionassem-no com a atividade proposta e seu cotidiano de trabalho, no caso dos que eram trabalhadores.

A atividade gerou muitas discussões por parte dos alunos, nas quais alguns expressaram que não eram atentos à importância do uso do EPI exigido pela empresa em que eram contratados, como também foi percebido que outros trabalhavam em empresas que não disponibilizavam o material completo. Após as discussões, os alunos compreenderam, com base em um senso mais crítico, a importância do uso desses equipamentos para sua saúde.

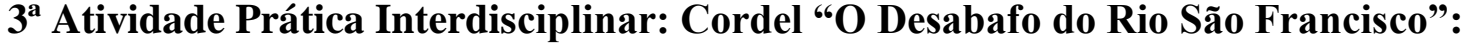

O cordel intitulado "O desabafo do rio São Francisco" (NASCIMENTO, 2010), de autoria do poeta Raimundo Luz Nascimento (1976-Atual), natural de Santa Maria da Boa Vista - PE e publicado no ano de 2010, foi trabalhado na aula de Biologia e na mesma semana foi desenvolvida uma oficina na aula de Língua Portuguesa pontuando os aspectos gramaticais do texto, como também foi aberto espaço para reflexão sobre as nossas atitudes com relação aos cuidados que devemos ter para a preservação do rio.

Os alunos expressaram suas reflexões e perceberam que, no cotidiano, ainda, há muito o que se fazer para contribuir com a não poluição do rio, tendo clareza a respeito dos motivos pelos quais isso é importante. Posterior às discussões, foi proposto, ainda na aula de Língua Portuguesa, uma oficina para confeccionar cartazes que tratassem da preservação do rio e cada aluno, ou grupo de alunos, desenvolveu sua produção, considerando as pontuações fomentadas na discussão.

\section{4a Atividade Prática Interdisciplinar: Vamos Evitar o Desperdício de Água:}

Trata-se de uma atividade prática realizada na aula de Biologia, cujo tópico foi proposto pelos alunos utilizando-se como material de discussão o panfleto informativo "Vamos Evitar o Desperdício de Água” disponibilizado pela Companhia Pernambucana de Saneamento e Abastecimento (COMPESA, 2013), que trata do desperdício de água, dos quantitativos em percentual de água doce, salgada e congelada, utilidades da água no nosso dia, impactos da água 
não tratada para nossa saúde e processos do tratamento de água. Na atividade foram discutidos os pontos apresentados no panfleto.

A discussão foi mediada por um dos alunos que, espontaneamente, disponibilizou-se para fomentá-la. Foi acordado com os alunos que os mesmos confeccionariam um cartaz pontuando a importância para o planeta da economia desse líquido precioso, com consequente redução da conta de água em suas residências.

\section{5a Atividade Prática Interdisciplinar: Dinâmica "Palavras a Favor do Meio Ambiente":}

Atividade trabalhada na aula de Biologia e desenvolvida em forma da dinâmica intitulada "Palavras a Favor do Meio Ambiente". Foram resgatadas as palavras do contexto das atividades práticas 1 e 2 em relação às quais os alunos haviam apresentado maior dificuldade quanto à escrita, à acentuação e à oralidade. A partir dessa demanda, surgiram os seguintes termos: desperdício, assoreamento, água potável, banho de rio, lavando o carro, fruticultura irrigada, economizar, preservação, meio ambiente e proteção ambiental.

Após o sorteio dos termos, foi solicitado que os alunos respondessem ao que era proposto e foi percebido que, quando o aluno respondia de forma escrita ao que estava sendo solicitado, ainda havia dúvidas quanto a como responder às perguntas da atividade. Com o auxílio da professora de Biologia, os alunos responderam à atividade e essa foi finalizada com a pontuação do que eles aprenderam a respeito dos termos apresentados no sorteio e que eles consideraram que pode ser levado consigo em forma de aprendizado prático.

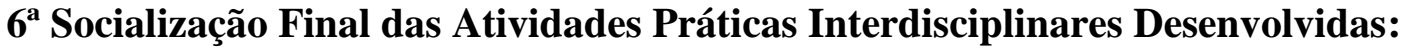

O encontro aconteceu no horário da aula de Biologia em que foi realizada a socialização de todas as atividades práticas trabalhadas em sala. Foi um momento de maior contribuição dos alunos em relação à pontuação da professora, pois havia a necessidade de ouvi-los para que fosse possível perceber o que eles haviam apreendido de conhecimento no decorrer de todas as práticas aplicadas em relação às temáticas de educação em saúde e meio ambiente.

Entrevista com alunos: a partir da realização das atividades, houve a segunda fase da entrevista com os alunos, emergindo as seguintes Categorias de Análise: 1) Efetivação de atividades práticas interdisciplinares; 2) Percepção da aprendizagem pelo método interdisciplinar com as disciplinas de Biologia e Língua Portuguesa; 3) Contribuições do método interdisciplinar na aprendizagem das temáticas de educação em saúde e meio ambiente trabalhadas. 
Segundo os alunos, a realização das atividades práticas interdisciplinares realizadas em sala apresentou semelhança com algumas das atividades aplicadas pelos professores no cotidiano escolar, porém foi externado por eles que as atividades que já haviam sido desenvolvidas acontecem de forma esporádica, mais especificamente, quando há realização de projetos:

Eu vim estudar nessa escola ano passado e do ano passado pra cá eu não tive essas atividades assim de estudar mais de uma disciplina ao mesmo tempo não, pra mim foi a primeira vez. Só uma professora de física que fez umas atividades junto com química, mas foi assim uma coisa rápida de 2 aulas Aluno 1.

Eu sinceramente não me lembro... porque aqui as aulas são tão rápidas que mal dá tempo dos professores darem as aulas deles, quando o professor pensa em começar a aula, pronto já acabou. E também tem professor que disse que não gosta de entrar no assunto de outro professor porque pode deixar a gente confuso - Aluno 2.

Aqui na escola já teve umas atividades assim, mas foi num projeto de Semana da Matemática, aí os professores passaram a semana toda dando suas aulas mais sempre que dava, eles mostravam umas porcentagens pra gente. Por exemplo: a professora de biologia tava dando uma aula que era sobre DSTs aí mostrava em porcentagem quantas pessoas já tinham sido contaminadas no Brasil. A de geografia mostrou pra gente qual o tamanho do Brasil, de Pernambuco e de Petrolina, era mais ou menos assim. Mais foi só na Semana de Matemática mesmo - Aluno 3.

Já teve uma atividade na minha turma ano passado, quando eu tava no primeiro módulo que o professor de história tava dando aula sobre os escravos aí eu achei muito interessante porque a de matemática tava dando uns cálculos pra gente e mostrou quantos escravos tinha vindo pra o Brasil quando o Brasil foi descoberto, mas eu nem lembro mais porque foi muito rápido, foi só em duas aulas mesmo de cada disciplina - Aluno 4.

Apresenta-se nas falas dos alunos 1, 2 e 4 que a realização de aulas voltadas para a prática interdisciplinar mostra-se deficiente devido ao tempo da hora/aula que os professores têm em sala para a realização de tal prática. Fazenda (2011) também ressalta que a tanto a falta de tempo no âmbito pessoal como em sala de aula é um fator que inibe a realização da prática interdisciplinar.

Foi percebido na pesquisa, mediante a fala das professoras, e conforme registrado no diário de bordo, que esse problema é mais agravante na EJA devido à hora/aula dessa modalidade de ensino ser reduzida em comparação ao ensino normal médio. Assim, sugere-se como alternativa para tal problema a reorganização curricular, pensando mais em sua realização prática do que meramente teórica em virtude da compactação da hora/aula e do hábito dos alunos de, na maioria das vezes, chegarem atrasados às aulas, quase sempre por questões de 
deslocamento, transporte e trabalho, problema culturalmente percebido na escola campo da pesquisa.

Diante de todos os fatores positivos para a realização das práticas interdisciplinares apresentados neste estudo, o tempo de preparo da ambiência para realizar as práticas foi também um dos desafios encontrados.

Fazenda (2011) ainda cita os obstáculos de ordem material como barreiras que existem entre as pessoas envolvidas no desencadear da prática interdisciplinar:

A prática da interdisciplinaridade exige uma nova articulação de espaço e tempo que favoreça os encontros e trabalhos em pequenos grupos, assim como os contatos individuais entre professores e estudantes (FAZENDA, 2011, p. 95).

O mesmo obstáculo apresentado pela autora também foi percebido no campo da pesquisa, tanto pelas professoras, como já citado neste trabalho, como também pelos alunos, ao afirmarem que o diálogo entre duas disciplinas realizadas pelo mesmo professor ocorreu de forma esporádica devido ao fator tempo de aula não ser suficiente para um trabalho mais abrangente.

O aluno 3 externou que houve uma prática semelhante à interdisciplinar por ter sido desenvolvido um projeto ofertado pela escola, correlacionando a interação da disciplina Matemática com as de Biologia e Geografia, mas, de acordo com a definição de interdisciplinaridade neste trabalho, percebemos que não foi aberto espaço para discussão a respeito da temática DSTs, fator esse fundamental para a prática interdisciplinar, conforme definição apresentada neste estudo.

Trabalho semelhante também foi observado nos estudos de Miranda et al. (2012). Nele, os autores propuseram atividades relacionadas com as disciplinas de Matemática e Educação Física a alunos de um curso do ProEJA. Além dos componentes numéricos, no estudo dos autores, também foi explorada a criticidade dos alunos quanto ao que estava sendo apresentado e acerca dos temas trabalhados.

Percepção de aprendizagem após a realização das práticas interdisciplinares: Diante do exposto em suas falas, todas as atividades foram desenvolvidas sem dificuldade em compreender o que estava sendo proposto. As dificuldades apontadas foram concernentes aos conhecimentos prévios que os mesmos declararam ter sobre os assuntos trabalhados, mas não em relação à prática interdisciplinar.

Os alunos também consideraram que as atividades práticas foram significativas para sua bagagem de conhecimento, em especial por ter sido oportunizado o diálogo em relação ao que 
eles traziam sobre o que era discutido. Podemos perceber que o termo "prática interdisciplinar" foi bem compreendido pelos alunos, conforme citado pelo aluno 7, e que essa metodologia foi considerada um instrumento facilitador na aquisição de conhecimento:

Eu gostei muito de como foram feitas as atividades. Gostei também de como foi diferente a gente fazer as oficinas com Português e Biologia ao mesmo tempo, pensei que ia ser mais difícil porque ia juntar duas matérias, mas eu gostei e gostei mais ainda porque a gente estudava e ia fazendo os cartazes e ainda teve a discussão sobre a poluição do rio e as regras de português ao mesmo tempo - Aluno 5.

Eu gosto muito de desenhar, e faço alguns desenhos só com o lápis e papel mesmo, nem precisa ser colorido, só que eu não costumo fazer desenhos com frases porque às vezes eu acho que vou está escrevendo errado, mas esse cartaz sobre a poluição do rio eu fiz confiante de que estava certo porque a professora ajudou. E também agora eu penso melhor sobre essa questão da poluição dos rios - Aluno 6.

Quando a senhora disse o nome do seu projeto e falou que eram sobre "Práticas Interdisciplinares" eu juro q não fazia nem ideia do que era rsrs... mas depois que a senhora explicou aí eu passei a entender mais ou menos só não entendia como ia ser quando a gente tivesse fazendo na prática, mas depois que a gente começou a fazer as atividades aí sim eu entendi direitinho o que era e achei muito fácil, a de Biologia já fez umas atividades parecidas, mas seria bem mais fácil pra gente se os outros professores fizessem também porque não fica só aquele negócio de livro e quadro, eu mesmo gosto muito de aulas que o professor faz debate porque o professor e os colegas também ficam sabendo de nossa opinião sobre o assunto. - Aluno 7.

Eu não tinha parado ainda pra pensar na ligação que as duas matérias podiam ter, muito interessante juntar a gramática de português com a ciência da biologia. Eu não tenho vocação para ser professora, mas se eu um dia eu fosse, também ia fazer atividades assim como essas com os meus alunos Aluno 8.

Em todas as falas dos alunos podemos perceber que o objetivo da prática interdisciplinar foi alcançado, pois a oportunidade para o diálogo com o que estava sendo proposto foi o que os alunos mais apreciaram em relação à postura das professoras no momento das atividades. Foi considerado também o que os discentes traziam como bagagem de conhecimento, sendo essa postura uma condição inerente da interdisciplinaridade, também conhecida pelo termo sine qua non, originado do latim e que só poderia ocorrer sob uma atitude interdisciplinar (FAZENDA, 2011).

Nota-se, nas falas dos alunos, que estava sendo assimilada a pauta sobre a poluição do rio, trazendo-os para a reflexão acerca de tal assunto. Pode-se perceber que a prática docente de forma crítica e construtiva, tão bem considerada pelo professor Luckesi (2006), foi posta em prática. Para o autor, e também mediante o conceito de interdisciplinaridade o qual respalda 
este trabalho, a prática docente de forma crítica considera os determinantes sociais em que o educando está inserido e a construtiva trabalha com princípios científicos e metodológicos, visando à construção do ensino e da aprendizagem para o desenvolvimento do educando.

Quanto ao que foi externado na fala do aluno 6, isso remete ao que Freire (1996, p.16), em sua obra "Pedagogia da Autonomia", afirma: "ensinar exige respeito aos saberes do educando". Quando o aluno traz consigo os saberes que foram socialmente construídos no decorrer de sua trajetória de vida, porque não aproveitar a experiência que tem esse aluno de viver em áreas da cidade descuidadas pelo poder público para discutir em sala de aula? Para Freire, alguns autores podem considerá-la como um questionamento demagógico da parte de quem o faz, mas o autor rebate a demagogia dessa pergunta ao mostrar que são necessários a crítica e o espaço para discussão dos assuntos pertinentes ao desenvolvimento intelectual dos alunos.

Para Freire (1996), desenvolver a criticidade do educando é fundamental para que esse possa opinar sobre o que está sendo discutido e possa vir a ter uma postura diante das questões trabalhadas no âmbito da educação e da vida. Isso foi percebido na discussão referente à poluição do rio, relatada pelos alunos 5 e 6 , quando eles externaram que, além da arte na criação dos cartazes, também houve espaço para uma reflexão pessoal sobre o assunto norteador da atividade.

Diante de todas as falas dos alunos, ficou evidente que há demanda para a prática interdisciplinar com os alunos da EJA, mesmo eles apresentando limitações de cunho científico. Ainda assim, deve-se considerar sua bagagem de conhecimento, mesmo que esse seja de cunho empírico, e assim proporcionar-lhes o conhecimento científico necessário à sua autonomia enquanto sujeito crítico (FREIRE, 2002).

\section{Contribuições da prática interdisciplinar na aprendizagem de educação em saúde e meio ambiente:}

Os alunos externaram que conseguiram compreender, sem grau de dificuldade, os conteúdos propostos nas atividades e sinalizaram que, se todas as disciplinas corroborarem com a prática interdisciplinar, haverá a possibilidade de melhores resultados na aquisição de conhecimentos.

No contexto das atividades práticas de educação em saúde, foi perceptível que as práticas aplicadas contribuíram de forma positiva para a aprendizagem dos alunos, 
considerando que eles, além do entendimento sobre o assunto, também refletiram sobre suas práticas cotidianas:

Eu já sabia que alguns alimentos não são saudáveis, mas sabe como é né... a gente não liga muito e acaba comendo, mas quando foi discutido dos riscos pra saúde depois de muito anos comendo errado, agora eu estou cuidando mais de minha alimentação. Também gostei de colocar no cartaz sobre a importância de fazer alguma atividade física. Só não estava segura na hora de colocar as frases no cartaz com as orientações porque ia ficar na parede da sala e se tivesse alguma palavra escrita errada todo mundo ia ver rsrs... mas a professora teve paciência e corrigiu os erros de português do meu grupo antes que a gente passasse do lápis pra o pincel-Aluno 9.

Eu gostei muito da atividade de alimentação saudável porque o panfleto dos 10 passos fala da importância da atividade física e muitas vezes a gente pensa que só comer certo é o suficiente, mas não é! Também temos que fazer alguma atividade física pra ter uma saúde melhor. Eu até comentei em casa com minha mãe que tem diabete e a médica dela disse q ela não podia comer um bocado de coisa e que tinha que fazer caminhada, mas ela acha que não precisa porque já tá na dieta, aí eu disse: Mãe, o Ministério da Saúde diz que é pra fazer atividade física também. Eu disse até que vou começar a fazer caminhada porque também tô precisando rsrs... - Aluno 10.

Eu achei muito boa a atividade do EPI, como a senhora sabe, eu sou eletricista e lá na empresa que eu trabalho a gente recebe o EPI antes de começar a trabalhar, só que outro dia tinha um capacete que tava trincado e o chefe do setor disse pra meu colega que dava pra ele usar aí eu lembrei do que a gente discutiu aqui na sala sobre essa atividade e disse pra ele: não patrão, não pode não, se acontecer alguma coisa com ele, quem vai se responsabilizar? - Aluno 11.

A apreensão do conhecimento quanto à temática de educação em saúde foi percebida nas falas dos alunos a partir do momento em que esses expressavam o que traziam de bagagem sobre a temática. O aluno 9 afirmou que, a partir do momento que foi "discutido" sobre os riscos de uma alimentação considerada inadequada, ele despertou para um maior cuidado com a própria saúde e, ao mesmo tempo, houve o cuidado da professora com a escrita correta das palavras no cartaz que estava sendo confeccionado. A oferta de um momento para dialogar sobre o que está sendo apresentado e simultaneamente trabalhar regras de ortografia concretiza o que é proposto por Fazenda (2011).

Esse momento de criticidade e de atenção com a Língua Portuguesa remete à postura da prática interdisciplinar tão bem defendida por Fazenda (2011), quando o autor apresenta que o fato de o Homem estar no mundo já o torna um ser Múltiplo e não Uno em relação ao mundo que o cerca.

Sobre essa ideia citada, a passagem do conhecimento à ação envolve uma série de fenômenos sociais e naturais. No caso do aluno 9, o contexto em que ele estava inserido em seu 
dia a dia somado a uma abordagem interdisciplinar pôde levá-lo a ação e essa é a abordagem da interdisciplinaridade na prática (FAZENDA, 2011).

A postura na fala do aluno 10 também apresenta que, embora já obtivesse algum conhecimento referente aos cuidados com a saúde, não havia sido despertada ainda a maturidade que o levasse à ação quanto à informação discutida na atividade prática. É importante que os professores estejam atentos a essas atitudes em nossos alunos na realização da prática interdisciplinar para que essa não fique aprisionada apenas ao que é desenvolvido na sala de aula.

O aluno 11 apresentou, em sua fala, também a criticidade quanto à postura de um profissional que atua na área de segurança elétrica ao se deparar com uma situação de risco da sua própria segurança e do colega no campo profissional, ao questionar o seu superior quanto aos riscos de trabalhar com falhas materiais em um dos equipamentos, que fazem parte do EPI. Foi percebido, na fala do aluno, que o que o motivou para tal questionamento foi um momento de reflexão sobre a temática mediante a atividade prática, e que se mostrou eficiente para instigar a criticidade do aluno no seu ambiente de trabalho.

Nesse momento, pode-se perceber, na pesquisa, a interdisciplinaridade defendida por Fazenda (2011), quando o professor foi capaz de agregar de forma prática uma teoria proposta mediante a atividade realizada em sala. Também é notória a teoria de Morin (2000), quando esse explica que toda a complexidade do ser humano deve ser considerada no contexto da educação que se propõe a ser pelo ensino interdisciplinar.

O aluno 11 também reporta em sua fala o que é discutido por Luckesi (2006), quando esse infere que os conhecimentos assimilados pelos educandos servem de suporte para a formação de habilidades, hábitos e convicções. Assim, "As habilidades [...] demonstram que cada educando tornou efetivamente seu os conhecimentos transmitidos, possibilitando autonomia e dependência" (LUCKESI, 2006, p. 127).

Em relação às atividades práticas desenvolvidas com a temática meio ambiente, os alunos compreenderam que ter um material prático de apoio para auxiliar na construção de uma atividade é um instrumento eficaz para expandir seus conhecimentos:

Na atividade do cordel, eu gostei muito porque a gente tava lendo um "cordel" e ao mesmo tempo, tudo que o autor falava era verdade! E mesmo sendo um cordel, a gente tava fazendo uma atividade que tratava da poluição do rio São Francisco e eu imaginando depois o quanto a gente polui esse rio e isso é algo muito sério, precisamos pensar mais nisso - Aluno 12.

Quando a gente fez o cartaz sobre a preservação do rio São Francisco, eu gostei muito porque eu ainda fico confuso com o tempo dos verbos e nessa 
atividade, a gente fez um cartaz de incentivo pra preservar o rio ao mesmo tempo que aprendia a conjugar os verbos, foi muito bom-Aluno 13.

A aula que a gente fez os cartazes sobre a poluição do rio e também a de recapitulação de tudo que a gente fez e aprendeu foi muito boa pra mim porque nessas atividades todas eu aprendi de um jeito diferente, sei lá, a gente podia dizer o que achava dos assuntos, eu gosto quando a aula é assim, tipo um debate, não dá nem pra sentir o cansaço do trabalho rs..., foi muito bom mesmo, até me senti mais motivado - Aluno 14.

Não são em todas as matérias que eu tenho dificuldade, é mais em português, matemática e inglês, mas se os professores dessas matérias fizessem umas aulas assim como essa de economizar água trazendo pra gente um folheto com informações assim fácil da gente entender e com tempo pra fazer debate como essas atividades que as professoras fizeram com a gente eu ficaria mais motivado e tiraria notas melhores. Mas não sei se isso depende da direção ou dos professores quererem fazer, aí tinha que ver com eles, né! - Aluno 15.

Os alunos 12, 13 e 14 afirmam que, apesar de a atividade tratar tanto da poesia no contexto literário quanto do uso correto da gramática, o assunto tornou-se mais fácil de ser compreendido, além de que, ainda, foi oportunizada a discussão do que estava sendo trabalhado na atividade prática para que os alunos pudessem externar sua bagagem de conhecimento trazida sobre o assunto. Foi percebido também que a professora mediou o debate sobre o assunto, aplicando de forma efetiva o conceito de interdisciplinaridade defendido neste trabalho.

Como educadores, e respaldados na concepção de Zabala (1998), os docentes devem perceber que o momento de escuta do professor em relação ao conhecimento prévio do aluno constitui-se na valorização dos conceitos empíricos que este traz consigo. O interesse do professor pelos saberes dos estudantes configura-se como um perfil de professor comprometido com a prática social crítica e em uma perspectiva dialética também defendida por Freire (1996).

Foi percebido que, durante a realização da atividade, a professora teve o cuidado de não desenvolver a atividade de forma tecnicista e metódica, postura essa criticada pelo professor Libâneo (1986), ao afirmar que, para superar a visão tecnicista, é preciso que o aluno desenvolva uma aptidão crítica do conteúdo e que o tecnicismo consiste na supervalorização dos conceitos técnicos em diminuição do discurso crítico do aluno. Ao superar-se a visão apenas conteudista, encaminhando os alunos para o contexto em que professor e aluno estão inseridos, é proporcionada a autonomia crítica do aluno.

Compartilhando da mesma concepção, Freire (1996) também critica o modelo de educação bancária, na qual o professor é mero transmissor de conhecimento e apenas ensina e o aluno apenas aprende e, nessa relação de educação verticalizada, o conceito de diálogo que 
pressupõe uma relação de escuta não existe, e sabe-se que, sem o diálogo, não há saber nem pesquisa.

Diante da afirmação dos alunos 14 e 15, que dizem gostar de aulas em forma de debate e que isso deixa-os mais motivados e até impede-os de sentirem-se cansados, pode-se perceber que há demanda para aulas em forma de debate como metodologia a ser aplicada em sala, ao mesmo tempo em que é fácil de aplicar a interdisciplinaridade, pois o professor não fica necessariamente restrito à forma como deve-se dar a aula ao mesmo tempo em que é possível inserir o conteúdo curricular proposto pela escola. Esse fator é notório nos alunos, visto que o conhecimento que eles trazem sobre o assunto passa a ser considerado como parte integrada do processo de aprendizagem (LUCKESI, 2006).

Os benefícios da discussão em sala são muitos; dentre alguns desses, podemos citar que avaliar o assunto da aula, sob diversos aspectos, estimula o aluno a ouvir de forma atenta e respeitosa, possibilita agilidade intelectual, os alunos passam a ser co-produtores de conhecimento, desenvolvem hábitos de aprendizagem cooperativa, dentre outros. Entretanto, cabe ressaltar que não se trata de um método que possa ser utilizado de forma indiscriminada para ensinar tudo e a todos: antes, deve-se adequá-lo para o alcance dos objetivos propostos (ZABALA, 2010).

De um modo geral, após a realização das atividades práticas interdisciplinares das duas temáticas, foi percebido neste trabalho o quanto os alunos dispõem-se a dialogar nas atividades a partir do momento em que lhes é oportunizado esse espaço. Também foi percebida uma importante bagagem de conhecimento empírico prévio - conhecimento resultante do senso comum, por vezes baseado na experiência, sem necessidade de comprovação científica - que os alunos trazem consigo mediante seu contexto histórico de vida.

Quanto a esse conhecimento prévio, deve-se dar valor à "aprendizagem histórica", uma vez que os alunos da EJA trazem a sua história de vida, que se configura como o resultado das experiências acumuladas em seu contexto histórico. É dessas aprendizagens históricas que o professor, ao contextualizá-las, deve partir para um ensino no qual o conteúdo deve estar impregnado de significância, em possibilidade de aplicação desses conhecimentos no cotidiano, em um processo de interesses entre o conhecimento empírico e o científico.

\section{Considerações finais}

A interdisciplinaridade consiste em um método de ensino que tem sido discutido em vários campos da educação e é compreendido na literatura como importante intervenção 
educativa e passível de questionamentos acerca da prática educativa. Entretanto, inserir a prática interdisciplinar no ato de ensinar é considerado um dos desafios para a educação, visto que esta tem por objetivo aguçar cada vez mais o prazer pelo novo conhecimento a ser adquirido.

Esse estudo buscou apresentar os resultados da aplicação da prática interdisciplinar com as temáticas de educação em saúde e meio ambiente na modalidade EJA de ensino, sendo perceptível a eficácia da interdisciplinaridade mediante as questões externadas pelos alunos nas entrevistas realizadas. Notou-se em suas falas a possibilidade de um novo olhar crítico acerca de mudanças em suas posturas com relação aos cuidados com a saúde e o meio ambiente

Assim, está claro que alunos da modalidade de ensino EJA necessitam de uma pedagogia que contemple práticas educativas que agucem seus interesses pelo conhecimento. Para tanto, um dos métodos que abarcam tal metodologia consiste no diálogo entre as diferentes áreas de ensino, superando a ideia de transmissão de conteúdos e caminhando para uma abordagem interdisciplinar para que as temáticas trabalhadas, bem como a prática trabalhada nos conteúdos, possam ser eficazes.

AGRADECIMENTOS: À Fundação de Amparo à Ciência e Tecnologia do Estado de Pernambuco (FACEPE) pela concessão de bolsa de estudo para viabilização da pesquisa.

\section{REFERÊNCIAS}

ARROYO, M. Formar educadoras e educadores de jovens e adultos. In: Formação de educadores de jovens e adultos. Organizado por Leôncio Soares. Belo Horizonte: Autêntica/SECAD-MEC/UNESCO, 2006.

BARDIN, L. Análise de Conteúdo. Lisboa: LDA, 2009.

BRASIL. Ministério da Saúde. Alimentação saudável: siga os 10 passos. 2013. Disponível em:

http://bvsms.saude.gov.br/bvs/publicacoes/guia_alimentar_alimentacao_saudavel_1edicao.pdf . Acesso em: 27 out. 2016.

BRASIL. Ministério da Educação e Cultura. Lei de Diretrizes e Bases da Educação Nacional. 1996. Disponível em:

http://portal.mec.gov.br/seesp/arquivos/pdf/lei9394_ldbn2.pdf. Acesso em: 12 set. 2016.

BRASIL. Ministério da Educação. Parâmetros Curriculares Nacionais. Apresentação dos temas transversais. Brasília, DF, 1997. 
CARBONELL, S. Educação estética na EJA: a beleza de ensinar e aprender com jovens adultos. $1^{\text {a }}$ Ed. São Paulo: Cortez. 2012. 152p.

COMPESA. Companhia Pernambucana de Saneamento. Vamos Evitar o Desperdício de Água. 2013. Disponível em: http://servicos.compesa.com.br/documentos-publicacoes-efolhetos/. Acesso em: 22 out. 2016.

FAZENDA. I. C. Interdisciplinaridade: história, teoria e pesquisa. $2^{\text {a }}$. ed. Campinas, SP: Papirus, 1994.

FAZENDA. I. C. Integração da interdisciplinaridade no ensino brasileiro. $6^{a}$ ed. São Paulo: Edições Loyala Jesuítas. 176p., 2011.

FAZENDA; I. C. A; GODOY, H. P. Interdisciplinaridade: pensar, pesquisar e intervir. 50 ed. São Paulo: Cortez, 285p., 2014.

FINO, C. N. Inovação pedagógica, etnografia, distanciação: etnografia da educação. Funchal: Universidade da Madeira, CIE-UMA, 2011.

FREIRE, P. Pedagogia da Esperança: um reencontro com a pedagogia do oprimido. Ed. Paz e Terra, S.A, Rio de Janeiro, 1996.

FREIRE, P. Pedagogia da Autonomia: saberes necessários à prática educativa. Ed. Paz e Terra, S.A, Rio de Janeiro, 2002.

FREIRE, P. Pedagogia do oprimido. 50. ed. Rio de Janeiro: Paz e Terra, 254p., 2011.

GIL, A. C. Como elaborar projetos de pesquisa. 4. ed. São Paulo: Atlas, 2007.

LIBÂNEO, J. C. Democratização da escola pública: a pedagogia histórico-crítico social dos conteúdos. São Paulo: Loiola, 1986.

LUCKESI, C. Avaliação da aprendizagem escolar: estudos e proposições. $18^{a}$ ed. São Paulo: Cortez, 2006.

MERLEAU-PONTY, M. Fenomenologia da percepção. 2. ed. São Paulo: Martins Fontes, 1999.

MIRANDA, P. R.; FARIA, R. C.; GAZIRE, E. S. Interdisciplinaridade no ensino de Matemática e Educação Física no PROEJA. Revista Zetetiké. FE/Unicamp, v. 20, n. 38, jul/dez 2012.

MORIN, E. Os sete saberes necessários à educação do futuro. 2. ed. São Paulo: Cortez, Brasília, DF: UNESCO, 2000.

NASCIMENTO, R. Desabafo do Rio São Francisco. 2010. Recanto das Letras. Disponível em: http://www.recantodasletras.com.br/cordel/2203645. Acesso em: 24 set. 2016.

SÃO PAULO (Estado). SECRETARIA MUNICIPAL DE EDUCAÇÃO. Diretoria de Orientação Técnica Divisão de Orientação Técnica - Educação de Jovens e Adultos. 
Educação de Jovens e Adultos: princípios e práticas pedagógicas. São Paulo, 2015. 40 p. temas transversais. Brasília: MEC, 1997.

SICRIVANO, C. N. et al. Ciência, transformação e cotidiano. São Paulo: Global. Coleção Viver e Aprender, 2013.

THIESEN, J. S. A interdisciplinaridade como um movimento articulador no processo ensinoaprendizagem. Revista Brasileira de Educação. Rio de Janeiro, v. 13, n. 39, p. 545-554, dez. 2008.

ZABALA, A. A prática educativa: como ensinar. Tradução: Ernani F. da F. Rosa. Porto Alegre: Artmed. Ano 1998. Reimpressão, 2010.

\section{Como citar este artigo:}

GUEDES, Elisa Angélica Alves; MENDES, Marianne Louise Marinho; MESSIAS, Cristhiane Maria Bazílio de Omena. Práticas interdisciplinares em educação em saúde e meio ambiente na Educação de Jovens e Adultos: percepção dos alunos. Revista Ibero-Americana de Estudos em Educação, Araraquara, v. 14, n. 3, p. 1030-1048, jul./set., 2019. e-ISSN: 1982-5587. DOI: 10.21723/riaee.v14i3.10064

Data de Submissão: 06/07/2017

Revisões requeridas: 30/01/2018

Aceite em: 20/03/2018

Publicado em: 25/03/2019 